PENGARUH KUALITAS PELAYANAN TERHADAP KEPUASAN NASABAH PADA PT. BANK RAKYAT INDONESIA (PERSERO) Tbk.

\author{
Oleh: \\ Samsul Rizal \\ Fakultas Ekonomi dan Bisnis- Prodi Manajemen-Universitas Muhammadiyah Makassar \\ E-mail: rizalsamsul09@unismuh.ac.id \\ Irwan Abdullah \\ Fakultas Ekonomi dan Bisnis- Prodi Manajemen-Universitas Muhammadiyah Makassar
}

E-mail: irwan.abdullah@unismuh.ac.id

\title{
Vivid Violin
}

Sekolah Tinggi Wirabakti Makassar

E-mail: vividviolin88@gmail.com,

\section{Eka Wardiana}

Fakultas Ekonomi dan Bisnis- Prodi Manajemen-Universitas Muhammadiyah Makassar E-mail: ekawardiana02@gmail.com

\begin{tabular}{l}
\hline Article Info \\
\hline Article History : \\
Received 06 August - 2021 \\
Accepted 12 Sept - 2021 \\
Available Online \\
25 Sept - 2021
\end{tabular}

Keyword:

Service Quality, Customer

Satisfaction, Ex-Post-

\section{Abstract}

This study aims to determine the effect of service quality on customer satisfaction. This research was conducted at PT. Bank Rakyat Indonesia (Persero) Tbk. Bengo Unit Watampone Branch with a population of 500 customers, while the sample size was determined by incidental sampling technique, namely 84 respondents. This type of research is quantitative with an ex-postfacto approach. Data was collected by direct observation, questionnaires, and literature study. Data analysis used descriptive statistical techniques, simple linear regression analysis, and hypothesis testing. The results showed that there was an effect of service quality on customer satisfaction at PT. Bank Rakyat Indonesia (Persero) Tbk. Watampone Branch Bengo Unit. The results of data analysis obtained from the $t$-count of 7.669, while the t-table of 1.98932, so that the t-test hypothesis of the service quality variable has a positive effect on customer satisfaction. From the SPSS calculation, $R=0.646$, with $R 2=0.418$ or $41.8 \%$, the amount of customer satisfaction has been described in the service quality data. While the remaining 0.582, or 58.2\%, information about the magnitude of customer satisfaction cannot be explained by the independent variables, In addition, the findings show that quite a variety of customers at PT. Bank Rakyat Indonesia (Persero) Tbk. Bengo Unit Watampone Branch in terms of gender, age, last education, and occupation. Therefore, these results can be used as a reference for further research related to the level of customer satisfaction, especially in organizations/companies 


\section{PENDAHULUAN}

Dunia perbankan Indonesia saat ini diwarnai dengan persaingan yang semakin ketat (Ariyanto, 2004; Wiradendi Wolor, 2020). Hal ini di karenakan semakin majunya lembaga-lembaga perbankan dan lembaga perkreditan yang berusaha menarik perhatian nasabah. Dengan semakin banyak lembaga perbankan dan lembaga perkreditan, sudah barang tentu masyarakat mempunyai berbagai alternatif dalam menggunakan jasa perbankan. Dalam upaya menciptakan kepuasan nasabah, pihak bank seharusnya melakukan evaluasi terhadap tingkat pelayanan yang diberikan kepada nasabah sehingga menghasilkan kepuasan nasabah terhadap bank yang dinaunginya. (Jariah, 2013; Murdifin, 2020).

Kepuasan adalah suatu proses yang dinamis secara berkala oleh suatu perusahaan manufaktur atau jasa (Halim et al., 2021; Setyaleksana et al., 2017). Karena pada dasarnya kepuasan inilah yang menghasilkan profit atau revenue pada perusahaan. Kepuasan dapat berubah, hal ini dikarenakan tingkat ekspektasi atau harapan semakin tinggi, sehingga menuntut adanya kualitas yang lebih (Yola \& Budianto, 2013; Ika Pratiwi \& Sugiarto, 2010). Meningkatnya tingkat pesaingan terutama dalam bidang perbankan, termasuk aktivitas promosi informasi dan janji yang diterima nasabah ini akhirnya menaikkan harapan nasabah (Sari, 2012; Pratiwi \& Soesanto, 2016; Eriyanti, 2021; Razak et al., 2018).

Oleh karena itu, salah satu upaya yang dilakukan oleh setiap perusahaan khususnya pada perusahaan yang bergerak di bidang jasa perbankan, tepatnya pada PT. Bank Rakyat Indonesia (Persero) Tbk. Unit Bengo Cabang Watampone adalah dengan menerapkan masalah kualitas pelayanan. Kualitas pelayanan adalah sebagai upaya pemenuhan kebutuhan dan keinginan konsumen atau nasabah serta ketepatan penyampaiannya dalam mengimbangi harapan nasabah (Trisusanti \& Karneli, 2017; Iskandar, 2012). Dimana dalam menunjang pengelolaan aktivitas perbankan maka perlu adanya tingkat pelayanan nasabah, sebab dengan adanya tingkat pelayanan nasabah maka akan memberikan kepuasan bagi nasabah.

Program pelayanan nasabah (Customer Service) di suatu bank bagi para nasabahnya khususnya pada PT. Bank Rakyat Indonesia (Persero) Tbk. Unit Bengo Cabang Watampone menyangkut faktorfaktor yang mempengaruhi penilaian nasabah atas pelayanan yang diterima seperti: penampilan dan kerapihan karyawan (bukti langsung), kemampuan karyawan dalam menanggapi masalah yang dihadapi nasabah (kehandalan), kesungguhan karyawan dalam membantu nasabah (daya tanggap), profesionalisme karyawan dalam bekerja (jaminan), keramahan dan kesopanan karyawan dalam menghadapi nasabah (empati). Pada dasarnya pelayananlah yang menjadi faktor terpenting dalam menentukan kepuasan nasabah (Pawestriningtyas \& Suyadi, 2016; Matzler et al., 2003; Rahi, \& Ishaq, 2020).

Demikian halnya dengan dengan pelayanan yang prima, nasabah akan merasa keanggotaanya memang dibutuhkan dan diperhatikan, sedangkan kepuasan atas pelayanan yang diberikan itu akan menumbuhkan dan meningkatkan loyalitas nasabah (Ishaq, 2017; Rangkuti, 2017. Loyalitas nasabah memang sangat dibutuhkan oleh bank karena pertumbuhan suatu bank itu sendiri sangat tergantung dari pertumbuhan dana yang berasal dari simpanan nasabah, karena kualitas pelayanan dirasakan memiliki hubungan dan dapat mempengaruhi kepuasan nasabah (Adamson et al., 2003; Rizan et al., 2014; Danupranata, 2014). Oleh karena itu, berdasarkan uraian sebelumnya sangat penting untuk dilakukan kajian tentang kualitas dan kepuasan nasabah khususnya di Bank. Penulis merumuskan masalah penelitian yaitu "Bagaimana pengaruh kualitas pelayanan terhadap kepuasan nasabah pada PT. Bank Rakyat Indonesia (Persero) Tbk".

\section{KAJIAN PUSTAKA DAN PENGEMBANGAN HIPOTESIS Pengertian Pelayanan}

Kasmir, (2005) mengemukakan bahwa: pelayanan adalah sebagai tindakan atau 
perbuatan seseorang atau organisasi untuk memberikan kepuasan kepada nasabah".

Fandy Tjiptono dan Gregorius Chandra, (2005) mengemukakan bahwa: konsep orientasi pelayanan lebih menekankan pada aspek praktik, kebijakan dan prosedur layanan pada sebuah organisasi. Sedangkan Brata (2003) mengeluarkan definisi yang berbeda dalam karyanya yang berjudul Dasar-Dasar Pelayanan Prima, mengatakan bahwa: suatu pelayanan akan terbentuk karena adanya proses pemberian layanan tertentu dari pihak penyedia layanan kepada pihak yang dilayani.

Brata, (2003). Selain itu Brata juga menambahkan bahwa suatu layanan dapat terjadi antara seseorang dengan seseorang, seseorang dengan kelompok, ataupun kelompok dengan seseorang seperti halnya orang-orang yang berada dalam sebuah organisasi yang memberikan layanan kepada orang-orang yang berada disekitarnya yang membutuhkan informasi organisasi tersebut.

\section{Kualitas Pelayanan}

Tjiptono (2011) Kualitas pelayanan jasa adalah tingkat keunggulan yang diharapkan dan pengendalian atas tingkat keunggulan tersebut untuk memenuhi keinginan pelanggan. Kualitas pelayanan ini adalah upaya pemenuhan kebutuhan yang dibarengi dengan keinginan konsumen serta ketepatan cara penyampaiannya agar dapat memenuhi harapan dan kepuasan pelanggan tersebut. Dalam kualitas pelayanan yang baik, terdapat beberapa jenis kriteria pelayanan, antara lain adalah sebagai berikut:

1. Ketepatan waktu pelayanan, termasuk didalamnya waktu untuk menunggu selama transaksi maupun proses pembayaran.

2. Akurasi pelayanan, yaitu meminimalkan kesalahan dalam pelayanan maupun transaksi.

3. Sopan santun dan keramahan ketika memberikan pelayanan.

4. Kemudahan mendapatkan pelayanan, yaitu seperti tersedianya sumber daya manusia untuk membantu melayani konsumen, serta fasilitas pendukung seperti komputer untuk mencari ketersediaan suatu produk.
Tjiptono, (2007) dalam Asdi (2012) yang berhasil memodifikasi kedelapan dimensi kualitas dari Garvin menjadi tujuh dimensi kualitas pelayanan yaitu:

1. Fungsi (Function), yaitu kinerja primer yang dituntut dari suatu pelayanan.

2. Karakteristik/ciri tambahan (Filtures), yaitu kinerja yang diharapkan atau karakteristik pelengkap.

3. Kesesuaian (Conformance), yaitu kepuasan yang didasarkan pada pemenuhan persyaratan yang telah ditetapkan.

4. Kehandalan (Reliability), yaitu kepercayaan dengan pelanggan dalam kaitan dengan waktu.

5. Dapat diperbaiki (Serviceability), yaitu kemampuan untuk melakukan perbaikan apabila terjadi kekeliruan.

6. Estetika (Aesthetics), Yaitu pengalaman pelanggan yang berkaitan dengan perasaan dan panca indra.

7. Persepsi (Perception), yaitu reputasi dari kualitas pelayanan.

Dalam salah satu studi mengenai service quality oleh Parasuraman (Lupiyoadi \& Hamdani, 2006) memiliki 5 dimensi, diantaranya adalah:

1. Tangible, Tangibles adalah bukti konkret kemampuan suatu perusahaan untuk menampilkan yang terbaik bagi pelanggan. Baik dari sisi fisik tampilan bangunan, fasilitas, perlengkapan teknologi pendukung, hingga penampilan

2. Reliability, Reliability adalah kemampuan perusahaan untuk memberikan pelayanan yang sesuai dengan harapan konsumen terkait kecepatan, ketepatan waktu, tidak ada kesalahan, sikap simpatik, dan lain sebagainya.

3. Responsiveness, Responsiveness adalah tanggap memberikan pelayanan yang cepat atau responsif serta diiringi dengan cara penyampaian yang jelas dan mudah dimengerti.

4. Assurance, Assurance adalah jaminan dan kepastian yang diperoleh dari sikap sopan santun karyawan, komunikasi yang baik, dan pengetahuan yang 
dimiliki, sehingga mampu menumbuhkan rasa percaya pelanggan.

5. Empathy, Empathy adalah memberikan perhatian yang tulus dan bersifat pribadi kepada pelanggan, hal ini dilakukan untuk mengetahui keinginan konsumen secara akurat dan spesifik.

\section{Kepuasan pelanggan}

Menurut Kotler dan A.B. Susanto (2000), kepuasan adalah tingkat kepuasan seseorang setelah membandingkan kinerja (hasil) yang dirasakan dibandingkan dengan harapan.

Tjiptono (2004) yang menyatakan bahwa "perusahaan yang gagal memuaskan pelanggannya akan menghadapi masalah yang lebih kompleks, umumnya pelanggan yang tidak puas akan menyampaikan pengalaman buruknya kepada banyak orang".

\section{METODE PENELITIAN}

Jenis penelitian yang digunakan adalah metode kuantitatif. Penelitian ini dilakukan di PT. Bank Rakyat Indonesia (Persero) Tbk. Unit Bengo Cabang Watampone. Waktu yang dibutuhkan dalam melakukan penelitian ini adalah kurang lebih 2 (dua) bulan. Populasi dalam penelitian ini adalah nasabah PT. Bank Rakyat Indonesia (Persero) Tbk. Unit Bengo Cabang Watampone sebanyak 500 nasabah. Sedangkan jumlah sampel sebanyak 84 responden ini diperkirakan telah memenuhi konsep keterwakilan semua nasabah PT. Bank Rakyat Indonesia (Persero) Tbk. Unit Bengo Cabang Watampone. Teknik penarikan sampel menggunakan teknik insidental sampling, artinya siapa saja yang ditemui pada saat penelitian maka akan dijadikan sampel (Taherdoost, 2016; Creswell \& Creswell, 2017).

Pengumpulan data yang dilakukan dalam penelitian ini terdiri atas, (1) Observasi langsung yaitu dengan cara mengamati langsung aktivitas serta mencatat yang dilakukan oleh perusahaan, (2) Kuesioner yang digunakan dalam bentuk tanda silang dimana responden memilih jawaban-jawaban yang tersedia dengan memberikan tanda silang pada jawaban yang dianggap paling sesuai, (3) Study kepustakaan (library research) yaitu mengumpulkan materi-materi yang digunakan sebagai landasan teori yang berkaitan dengan masalah yang ada atau landasan teori yang berkaitan dengan masalah yang ada atau landasan teori yang berkaitan dengan masalah yang diteliti terutama mengenai pengaruh kualitas pelayanan untuk memberikan solusi dari permasalahan yang ada pada PT. Bank Rakyat Indonesia (Persero) Tbk. Unit Bengo Cabang Watampone.

Data yang berhasil dikumpulkan, kemudian akan dianalisis dengan metode regresi berganda. Untuk menguji pengaruh variabel independen yaitu pengaruh kualitas pelayanan terhadap variabel dependen yaitu kepuasan nasabah pada PT. Bank Rakyat Indonesia (Persero) Tbk. Unit Bengo Cabang Watampone. Sebelum dilakukan pengujian dengan regresi berganda, terlebih dahulu dilakukan pengujian dengan beberapa teknik untuk menganalisis data sebagai persyaratan dari metode regresi sederhana. Selanjutnya dilakukan uji hipotesis (uji T) untuk menunjukkan seberapa jauh pengaruh satu variabel penjelas/independen seacara individual dalam menerangkan variasi variabel dependen.

\section{HASIL DAN PEMBAHASAN}

Berdasarkan rumusan masalah penelitian yaitu bagaimana pengaruh kualitas pelayanan terhadap kepuasan nasabah pada PT. Bank Rakyat Indonesia (Persero) Tbk. Hasil temuan yang disajikan cukup beragam baik dari jenis kelamin, umur, pendidikan terakhir, dan pekerjaan. Dalam penelitian ini menggunakan metode regresi sederhana. Untuk pengelahan data menggunakan software SPSS 20. Berikut akan di jelaskan dan dapat dilihat pada penjelasan tiap terlebih dahulu karakteristik responden dalam penelitian ini, yaitu berdasarkan jenis kelamin, umur, pendidikan terakhir, dan pekerjaan.

\section{Berdasarkan jenis kelamin}

Tingkat jenis kelamin responden yang ada pada PT. Bank Rakyat Indonesia (Persero) Tbk. Unit Bengo Cabang Watampone di uraikan sebagai berikut.

Berdasarkan hasil analisis data, diperolah data dari 84 responden. Bahwa 
jumlah responden berdasarkan jenis kelamin yang terbanyak adalah jenis kelamin perempuan sebanyak 53 responden atau sebesar $63,1 \%$. Sedangkan jenis kelamin laki-laki sebanyak 31 responden atau sebesar 36,9\%. Berdasarkan jenis kelamin yang terbanyak adalah jenis kelamin perempuan dikarenakan perempuan yang memegang dan menyimpan penghasilan yang di dapat dari pendapatan suami dan menabungnya ke bank yang telah ia percayai.

\section{Berdasarkan umur}

Tingkat umur responden yang ada pada PT. Bank Rakyat Indonesia (Persero) Tbk. Unit Bengo Cabang Watampone di uraikan sebagai berikut.

Berdasarkan hasil analisis data, komposisi tingkat umur responden yang terbanyak adalah berada pada tingkat umur 21 - 30 tahun sebanyak 28 responden dengan persentase sebesar $33,3 \%$. Kemudian dengan tingkat umur yang terbanyak berada pada masa produktif dimana, dimasa ini responden telah bekerja dan mendapatkan uang sendiri dari hasil keringatnya sendiri kemudian dengan penghasilan yang di dapatnya itu di tabungkan ke bank.

\section{Berdasarkan pendidikan terakhir}

Tingkat pendidikan terakhir responden yang ada pada PT. Bank Rakyat Indonesia (Persero) Tbk. Unit Bengo Cabang Watampone dapat dilihat pada tabel berikut ini.

Berdasarkan analisis data, tingkat pendidikan terakhir responden yang terbanyak adalah tingkat pendidikan SMA/Sederajat yakni sebanyak 34 responden dengan persentase sebesar 40,5\%. Di lihat dari tingkat pendidikan terakhir nasabah yang berada pada tingkat SMA/sederajat masih minim sekali dan lebih memutuskan untuk menikah di usia dini dan tidak memanfaatkan untuk mencapai pendidikan agar supaya dapat menjamin kesuksesannya.

\section{Bedasarkan pekerjaan}

Tingkat pendidikan terakhir responden yang ada pada PT. Bank Rakyat Indonesia
(Persero) Tbk. Unit Bengo Cabang Watampone dijelaskan berikut ini.

Berdasarkan analisis data SPSS 20, jumlah responden yang terbanyak berdasarkan pekerjaan adalah dari kalangan ibu rumah tangga yakni sebanyak 32 responden dengan persentase sebesar 38,1\%. Kemudian dari tingkat pekerjaan lebih banyak dari kalangan ibu rumah tangga yang menjadi nasabah dikarenakan uang dan pendapatan suami maupun penghasilan yang di dapat sendiri mereka yang memegang dan mengelolah keuangan dalam rumah tangga mereka dan sebagian penghasilan dan pendapatan di tabungkan ke bank yang terdekat dan telah mereka percayai dari tingkat keamanannya.

Selanjutnya dilakukan uji hipotesis yaitu dengan Analisis Regresi Liner Sederhana Selanjutnya akan dilakukan pengolahan data dengan menggunakan metode analisis data regresi liner sederhana dengan bantuan SPSS. Analisis regresi linear sederhana merupakan hubungan antara dua variabel yaitu variabel bebas (variable independen) dan variabel tidak bebas (variable dependen).

Regresi linear sederhana digunakan untuk mendapatkan hubungan matematis dalam bentuk suatu persamaan antara variabel tidak bebas dengan variabel bebas. Bentuk umum dari persamaan regresi linear untuk populasi adalah:

Dimana:

$$
\mathrm{Y}=\mathrm{a}+\mathrm{bx}+\mathrm{e}
$$

$$
\begin{aligned}
\mathrm{Y} & =\text { Kepuasan Konsumen } \\
\mathrm{a} & =\text { Konstanta } \\
\mathrm{b} & =\text { Koefisien variabel } \\
\mathrm{x} & =\text { Kualitas Pelayanan } \\
\mathrm{e} & =\text { Error/Faktor Kesalahan }
\end{aligned}
$$

Dalam melakukan perhitungan analisis regresi linear semua data diolah menggunakan aplikasi SPSS versi 20. Adapun hasil analisis data yang diperoleh dari pengolahan data SPSS adalah sebagai berikut (Lihat Tabel 1): 
Tabel 1. Model Summary

\begin{tabular}{|c|c|c|c|c|c|c|c|c|c|}
\hline \multirow[b]{2}{*}{ Model } & \multirow[b]{2}{*}{$\mathrm{R}$} & \multirow[b]{2}{*}{ R Square } & \multirow[b]{2}{*}{ Adjusted R Square } & \multirow{2}{*}{$\begin{array}{l}\text { Std. Error of } \\
\text { the Estimate }\end{array}$} & \multicolumn{5}{|c|}{ Change Statistics } \\
\hline & & & & & $\begin{array}{l}\text { R Square } \\
\text { Change }\end{array}$ & F Change & df1 & df 2 & $\begin{array}{c}\text { Sig. F } \\
\text { Change }\end{array}$ \\
\hline 1 &, $646^{\mathrm{a}}$ & ,418 & ,411 & 2,033 & ,418 & 58,806 & 1 & 82 & ,000 \\
\hline
\end{tabular}

Sumber: Hasil olah data SPSS 20

Dari hasil perhitungan SPSS diperoleh $\mathrm{R}$ $=0,646$, dengan $R^{2}=0,418$. Nilai $R$ merupakan hubungan antara kualitas pelayanan dan kepuasan nasabah, sedangkan untuk mengetahui seberapa besar kualitas model regresi linear yang terbentuk, maka diperhatikan nilai koefisien determinasi ( $\mathrm{R}$ square) $=0,418$, Nilai tersebut menunjukkan informasi bahwa $41,8 \%$, dari besarnya kepuasan nasabah telah dijelaskan pada data kualitas pelayanan. Sedangkan sisanya yaitu $58,2 \%$ informasi mengenai besarnya kepuasan nasabah belum dapat dijelaskan oleh variabel-variabel bebas tersebut.

Tabel 2. Coefficients

\begin{tabular}{|r|r|r|r|r|r|}
\hline \multirow{2}{*}{ Model } & \multicolumn{2}{|c|}{ Unstandardized Coefficients } & Standardized Coefficients & \multirow{2}{*}{ T } & Sig. \\
\cline { 2 - 5 } 1 & B & Std. Error & Beta & 1,692 &, 095 \\
(Constant) & 3,341 & 1,975 &, 053 &, 000 \\
\hline
\end{tabular}

Sumber: Hasil olah data SPSS 20

Pada tabel 4.9 tersebut, digunakan untuk melihat uji koefisien. Diketahui bahwa nilai signifikan untuk pengaruh kualitas pelayanan $(X)$ terhadap kepuasan nasabah $(\mathrm{Y})$ adalah sebesar $0,000<0,05$ dari hasil $\mathrm{t}$ hitung $7.669>\mathrm{t}$ tabel sebesar 1.98932, sehingga dapat disimpulkan hahwa kualitas pelayanan memiliki pengaruh yang positif terhadap kepuasan nasabah. Taraf kesalahan sebesar $5 \%$ atau 0,05 , maka akan dilakukan dengan uji hipotesis:

Ho = ada pengaruh kualitas pelayanan terhadap kepuasan nasabah PT. Bank Rakyat Indonesia (Persero) Tbk. Unit Bengo Cabang Watampone.

$\mathrm{Ha}=$ tidak ada pengaruh kualitas pelayanan terhadap kepuasan nasabah PT. Bank Rakyat Indonesia (Persero) Tbk. Unit Bengo Cabang Watampone.

Dari nilai persamaan yang dihasilkan oleh regresi diperoleh nilai persamaan sebagai berikut:

a. Kinerja karyawan $=7,669+0,404$

b. Nilai konstanta sebesar 1,692 dan dinyatakan jika tidak ada variabel bebas maka kepuasan nasabah juga sebesar 1,692 .

c. Nilai koefisien sebesar 0,404 dan menunjukkan bahwa meningkatnya kualitas pelayanan sebesar $1 \%$ dan akan meningkatkan kepuasan nasabah sebesar 0,404.

Nilai uji $\mathrm{t}$ menunjukkan bahwa tingkat signifikan konstanta dan variabel independen, sig $=0,000<0,05$ ini mempengaruhi secara signifikan dalam regresi linear sederhana.

Dengan demikian pengujian statistik ini dapat disimpulkan bahwa terdapat pengaruh signifikan kualitas pelayanan terhadap kepuasan nasabah pada PT. Bank Rakyat Indonesia (Persero) Tbk. Unit Bengo Cabang Watampone yang di tunjukkan dengan angka yang signifikan $0,00<0,05$ ada tabel model summary berdasarkan hasil analisis yang telah dilakukan, maka hipotesis yang diajukan sebelumnya dinyatakan dapat diterima.

\section{Pembahasan Hasil Penelitian}

Ketika nasabah sudah memutuskan dan mempunyai pilihan bank tentang tempat 
untuk menyimpan uang, maka akan memperhatikan aspek-aspek apakah yang menjadi pertimbangan utama dalam memilih, selain aspek program dan besarnya bunga bank tetapi juga kualitas pelayanan yang diberikan oleh karyawannya (Listiana, 2011; Adamson et al., 2003).

Kualitas pelayanan ini bukanlah bersifat permanen, melainkan juga dapat dirubah. Perubahan yang dilakukan itu berupa perubahan kualitas pelayanan agar semakin lebih baik lagi dan mendapat respon positif dari pelanggan. Dalam proses perubahan kualitas pelayanan diperlukan beberapa hal dalam menunjang prosesnya. Misalnya melakukan survei dan observasi kepada pelanggan, termasuk didalamnya berupa masukan, pendapat maupun feedback tentang pelayanan yang telah diberikan kepada nasabah (Mawey et al., 2018; Crow et al., 2002).

Kualitas pelayanan disini menjadi penting karena akan berdampak langsung kepada citra perusahaan (Crow et al., 2002). Jika kualitas pelayanan yang baik di berikan kepada nasabah atau pelanggang maka akan memberikan dampak positif bagi perusahaan dan membuat pelanggang akan tetap setia kepada perusahaan tersebut, dan jika pelanggang merasa puas atas pelayanan yang diberikan maka pelanggang juga akan membantu mengalirkan nasabah-nasabah baru kepada perusahan dengan bantuan informasi dan pengalaman yang diterimanya dari sebuah perusahaan (Mawey et al., 2018). Jenis-jenis pelayanan yang dapat diberikan misalnya berupa kemudahan, kecepatan, kemampuan, jaminan keamanan dan keramahtamahan yang ditunjukkan melalui sikap dan tindakan langsung kepada konsumen.

\section{KESIMPULAN}

Berdasarkan pada hasil analisis data mengenai pengaruh kualitas pelayanan terhadap kepuasan nasabah dimana hasil pengujian terhadap hipotesis Ho menunjukkan bahwa ada pengaruh kualitas pelayanan terhadap kepuasan nasabah PT. Bank Rakyat Indonesia (Persero) Tbk. Unit Bengo Cabang Watampone. Nilai koefisien kualitas pelayanan sebesar 0,404 dengan nilai t hitung $7.669>\mathrm{t}$ tabel sebesar 1.98932
Menurut Tjiptono, upaya pemenuhan kebutuhan yang dibarengi dengan keinginan konsumen serta ketepatan cara penyampaiannya agar dapat memenuhi harapan dan kepuasan pelanggan tersebut. Tjiptono (2011) Kualitas pelayanan jasa adalah tingkat keunggulan yang diharapkan dan pengendalian atas tingkat keunggulan tersebut untuk memenuhi keinginan pelanggan. Kualitas pelayanan ini adalah upaya pemenuhan kebutuhan yang dibarengi dengan keinginan konsumen serta ketepatan cara penyampaiannya agar dapat memenuhi harapan dan kepuasan pelanggan tersebut.

Fandy Tjiptono dan Gregorius Chandra (2005) mengemukakan bahwa: konsep orientasi pelayanan lebih menekankan pada aspek praktik, kebijakan dan prosedur layanan pada sebuah organisasi. Sedangkan Brata mengeluarkan definisi yang berbeda dalam karyanya yang berjudul Dasar-Dasar Pelayanan Prima, mengatakan bahwa: suatu pelayanan akan terbentuk karena adanya proses pemberian layanan tertentu dari pihak penyedia layanan kepada pihak yang dilayani." (Brata, 2003). Selain itu Brata juga menambahkan bahwa suatu layanan dapat terjadi antara seseorang dengan seseorang, seseorang dengan kelompok, ataupun kelompok dengan eseorang seperti halnya orang-orang yang berada dalam sebuah organisasi.

Berdasarkan hasil analisis dan pembahasan penulis menyimpulkan bahwa kualitas pelayanan mempunyai pengaruh positif terhadap kepuasan nasabah di PT. Bank Rakyat Indonesia (Persero) Tbk. Unit Bengo Cabang Watampone, hal ini dikarenakan kualitas pelayanan yang menimbulkan tekanan yang dapat mempengaruhi kepuasan nasabah.

dan tingkat signifikan sebesar 1\%. Hal ini menunjukkan bahwa kualitas pelayanan berpengaruh terhadap kepuasan nasabah. Dengan demikian hal ini membuktikan bahwa tindakan pelayanan yang dilakukan memberikan pengaruh yang posistif terhadap kepuasan nasabah. 


\section{REFERENSI}

Adamson, I., Chan, K. M., \& Handford, D. (2003). Relationship marketing: customer commitment and trust as a strategy for the smaller Hong Kong corporate banking sector. International journal of bank marketing.

Ariyanto, T. (2004). Profil persaingan usaha dalam industri perbankan Indonesia. Jurnal Keuangan dan Perbankan, 6(2).

Asdi. 2012. Pengaruh Dimensi Kualitas Pelayanan Terhadap Kepuasan Pasien Pada Rumah Sakit Umum Daerah Syekh Yusuf Sungguminasa Kabupaten Gowa. Jurnal Manajemen Profitability. Makassar.

Brata. 2003. Dasar-Dasar Pelayanan Prima. Editor Rayendra L. Toruan. Jakarta: Penenrbit PT Elex Media Komputindo Kelompok Gramedia

Creswell, J. W., \& Creswell, J. D. (2017). Research design: Qualitative, quantitative, and mixed methods approaches. Sage publications.

Crow, H., Gage, H., Hampson, S., Hart, J., Kimber, A., Storey, L., \& Thomas, H. (2002). Measurement of satisfaction with health care: Implications for practice from a systematic review of the literature. Health technology assessment.

Danupranata, G. (2013). Buku Ajar Manajemen Perbankan Syariah. Salemba Empat.

Eriyanti, H. (2021). Pengaruh Produk, Promosi, dan Kualitas Layanan Terhadap Kepuasan dan Loyalitas Nasabah Simpanan PT. Bank Muamalah Indonesia, Tbk. Cabang Pangkalpinang. JURNAL

MANAJEMEN

$D A N$ INVESTASI, 3(1), 83-95.

Halim, F., Kurniullah, A. Z., Butarbutar, M., Efendi, E., Sudarso, A., Purba, B., ... \& Novela, V. (2021). Manajemen Pemasaran Jasa. Yayasan Kita Menulis.

Ishaq, F. A. (2017). Analisis Strategi Pelayanan Prima Dalam Meningkatkan Loyalitas Nasabah
Pada BMT UGT Sidogiri Kantor Cabang Lodoyo Kabupaten Blitar.

Iskandar, D. (2012). Pengaruh Kualitas Pelayanan Terhadap Loyalitas Nasabah Dengan Kepuasan Dan Kepercayaan Nasabah Sebagai Variabel Intervening (Studi Empiris Nasabah Pd. Bank Perkreditan Rakyat Bkk Boyolali Kota). ProBank, 20(23).

Kasmir. 2005. Etika Custumer Service. edisi pertama. cetakan pertama. Jakarta: Penerbit Raja Grafindo Persada.

Kotler Philip dan A.B. Susanto. 2000. Manajemen Pemasaran, Edisi Kesebelasan Jilid 1, Alih Bahasa Benyamin Molan, Editor Yenna Waldemas. Jakarta Indeks.

Ika Pratiwi, D., \& Sugiarto, S. (2010). Analisis pengaruh harapan pelanggan, kualitas produk, kepuasan pelanggan terhadap loyalitas pelanggan internet flash unlimited di Semarang (Doctoral dissertation, Universitas Diponegoro).

Jariah, A. (2013). Analisis suku bunga kredit dan kualitas pelayanan serta pengaruhnya terhadap loyalitas nasabah pada bpr di lumajang. Wiga: Jurnal Penelitian Ilmu Ekonomi, 3(2), 1-19.

Listiana, E. (2011). Respon Nasabah Terhadap Product Positioning Tabungan Bank KALBAR. Jurnal Administrasi Bisnis, 7(1).

Lupiyoadi, H., \& Hamdani, A. (2006). Manajemen Pemasaran Jasa, Edisi Kedua. Jakarta: Penerbit Salemba Empat, 525.

Matzler, K., Sauerwein, E., \& Heischmidt, K. (2003). Importance-performance analysis revisited: the role of the factor structure of customer satisfaction. The Service Industries Journal, 23(2), 112-129.

Mawey, T. C., Tumbel, A., \& Ogi, I. W. (2018). Pengaruh Kepercayaan Dan Kualitas Layanan Terhadap Kepuasan Nasabah PT Bank Sulutgo. Jurnal EMBA: Jurnal Riset Ekonomi, Manajemen, Bisnis dan Akuntansi, 6(3). 
Murdifin, I. (2020). Pengaruh Kualitas Pelayanan Terhadap Kepuasan Nasabah Pada PT. Bank Danamon Cabang Makassar. Celebes Equilibrum Journal, 1(2), 23-33.

Pawestriningtyas, N. C., \& Suyadi, I. (2016). Pengaruh Kualitas Pelayanan Jasa Terhadap Kepuasan Nasabah (Survei Pada Nasabah Perum Pegadaian Kantor Cabang Syariah Tlogomas Malang). Jurnal Administrasi Bisnis, 32(2), 39-46.

Pratiwi, D., \& Soesanto, H. (2016). Analisis Pengaruh Atribut Tabungan, Mutu Tabungan dan Promosi Penjualan terhadap Citra Perusahaan dalam Meningkatkan Minat Menabung Nasabah Tabungan (Studi Kasus pada Bank Jateng Cabang Kordinator Semarang). Diponegoro Journal of Management, 5(2), 244-258.

Rahi, S., \& Ishaq, M. (2020). Factors Influencing online Shopping behavior With Mediating Role of Customer Perceived Value. Economic and Social Development: Book of Proceedings, 128-141.

Rangkuti, F. (2017). Customer care excellence: meningkatkan kinerja perusahaan melalui pelayanan prima plus analisis kasus jasa raharja. Gramedia Pustaka Utama.

Razak, A., Baheri, J., \& Ramadhan, M. I. (2018). Pengaruh Kepuasan dan Kepercayaan terhadap Loyalitas Nasabah pada Bank Negara Indonesia (BNI) Cabang Kendari. Sigma: Journal of Economic and Business, 1(79), 10-20.

Rizan, M., Warokka, A., \& Listyawati, D. (2014). Relationship marketing and customer loyalty: do customer satisfaction and customer trust really serve as intervening variables?. Journal of Marketing Research \& Case Studies, 2014, 1.

Sari, N. (2012). Manajemen Marketing (Pemasaran) Produk Jasa Keuangan Perbankan dalam Perspektif Islam. Media Syari'ah: Wahana Kajian Hukum Islam dan Pranata Sosial, 14(2), 199-212.
Setyaleksana, B. Y., Suharyono, S., \& Yulianto, E. (2017). Pengaruh Customer Relationship Management (CRM) Terhadap Kepuasan Dan Loyalitas Pelanggan (Survei pada Pelanggan GraPARI Telkomsel di Kota Malang). Jurnal Administrasi Bisnis, 46(1), 45-51.

Taherdoost, H. (2016). Sampling methods in research methodology; how to choose a sampling technique for research. How to Choose a Sampling Technique for Research. SSRN. http://dx.doi.org/10.2139/ssrn.32050 35

Tjiptono. 2011. Sistem Manajemen Strategic. Jakarta.

Tjiptono, Fandy. 2004. Prinsip-Prinsip Total Quality Service. Yogyakarta: Andi Offset.

Tjiptono, Fandy dan Anastasia Diana. 2003. Total Quality Manajemen. Edisi Revisi. Andy: Yogyakarta

Tjiptono, Fandy dan Gregorius Chandra. 2005. Service, Quality dan Satisfaction. Penerbit: Andi, Yogyakarta

Trisusanti, Y., \& Karneli, O. (2017). Pengaruh Kualitas Pelayanan dan Kepercayaan Terhadap Loyalitas Nasabah (Studi pada Bank BNI Syariah Kantor Cabang Pekanbaru) (Doctoral dissertation, Riau University).

Wiradendi Wolor, C. (2020). Implementation talent management to improve organization's performance in Indonesia to fight industrial revolution 4.0. International Journal of Scientific \& Technology Research.

Yola, M., \& Budianto, D. (2013). Analisis kepuasan konsumen terhadap kualitas pelayanan dan harga produk pada supermarket dengan menggunakan metode Importance Performance Analysis (IPA). Jurnal Optimasi Sistem Industri, 12(12), 301-309. 